\title{
Integration of SAE Student Competition with Project Course
}

\section{Mr. Marc Poynter, Indiana University Purdue University, Indianapolis}

Graduate Student at IUPUI.

\section{Swapnil Bansode}

Mr. Tejesh Charles Dube, Indiana University Purdue University, Indianapolis

I am a Mechanical Engineering graduate student interested in structural and material science application in the field of mechanical engineering

\section{Mr. Michael Golub, Indiana University Purdue University, Indianapolis}

Michael Golub is the Academic Laboratory Supervisor for the Mechanical Engineering department at IUPUI. He is an associate faculty at the same school, and has taught at several other colleges. He has conducted research related to Arctic Electric Vehicles and 3D printed plastics and metals. He participated and advised several student academic competition teams for several years. His team won 1st place in the 2012 SAE Clean Snowmobile Challenge. He has two masters degrees: one M.S. in Mechanical Engineering and an M.F.A. in Television Production. He also has three B.S. degrees in Liberal Arts, Mechanical Engineering, and Sustainable Energy.

\section{Dr. Jing Zhang, Indiana University Purdue University, Indianapolis}

Dr. Jing Zhang's research interests are broadly centered on understanding the processing-structureproperty relationships in advanced ceramics and metals for optimal performance in application, and identifying desirable processing routes for its manufacture. To this end, the research group employs a blend of experimental, theoretical, and numerical approaches, focusing on several areas, including:

1. Processing-Microstructure-Property-Performance Relationships: thermal barrier coating, solid oxide fuel cell, hydrogen transport membrane, lithium-ion battery 2. Physics-based Multi-scale Models: ab initio, molecular dynamics (MD), discrete element models (DEM), finite element models (FEM) 3. Coupled Phenomena: diffusion-thermomechanical properties 4. Additve Manufacturing (AM) or 3D Printing: AM materials characterization, AM process (laser metal powder bed fusion, ceramic slurry extrusion) design and modeling

(http://www.engr.iupui.edu/ jz29/) 


\title{
Integration of SAE Student Competition with Project Course
}

\begin{abstract}
In the past, the project courses at our university do not have any metrics to measure their success in a real-world environment. We recently merged a few capstone design teams with the Society of Automotive Engineers (SAE) student competitions. The outcome and benefit of the change are clear. The students are more motivated and willing to adopt new technologies in their project courses. Through competitions, students learned how to complete the project in the context of system. The paper describes the technical details that the student team learned throughout the 2019 competition.
\end{abstract}

\section{Background}

Our university was donated a 2017 Polaris Switchback Assault to compete in the 2019 Society of Automotive Engineers Clean Snowmobile Challenge. Snowmobile users, CSC judges, and the snowmobile industry is the audience for the innovations of this project. Modifications were made to make the snowmobile quieter, cleaner, and more fuel efficient. Noise levels were reduced by choosing a noise dampening muffler and utilizing sound absorbing material in key places. A three-way catalyst was used to reduce emission levels. Fuel efficiency was increased by making modifications of the ECU using a Dynojet Power Commander V (PCV) and Dynojet Autotune. The result of these modifications is an environmentally friendly snowmobile that can be operated in sensitive areas.

\section{Design details}

\subsection{ECU Remapping}

The ECU of the snowmobile was modified using a Dynojet Power Commander V (PCV) and Dynojet Autotune. Communication to the Engine's Electronic Control Unit (ECU) was made by the PCV. The PCV was mounted to the outside of the oil tank on the left side of the machine right under the side panel and wired connections were made to the ECU which made this a quick access point for later adjustments. Currently, we can connect to the PCV with a computer installed with the software to control the ECU. The throttle position at each engine RPM was able to be modified using this software and the matrix shown in Figure 1. The figure data will be updated later.

\begin{tabular}{|c|c|c|c|c|c|c|c|c|c|c|c|}
\hline & & \multicolumn{10}{|c|}{ THROTTLE POSSITION } \\
\hline & & 0 & 2 & 5 & 10 & 15 & 20 & 40 & 60 & 80 & 100 \\
\hline \multirow{19}{*}{ RPM } & 0 & 0 & 0 & 0 & 0 & 0 & 0 & 0 & 0 & 0 & 0 \\
\hline & 500 & 0 & 0 & 0 & 0 & 0 & 0 & 0 & 0 & 0 & 0 \\
\hline & 1000 & 0 & 0 & 0 & 0 & 0 & 0 & 0 & 0 & 0 & 0 \\
\hline & 1500 & 0 & 0 & 0 & 0 & 0 & 0 & 0 & 0 & 0 & 0 \\
\hline & 2000 & 0 & 0 & 0 & 0 & 0 & 0 & 0 & 0 & 0 & 0 \\
\hline & 2500 & 0 & 0 & 0 & 0 & 0 & 0 & 0 & 0 & 0 & 0 \\
\hline & 3000 & 0 & 0 & 0 & 0 & 0 & 0 & 0 & 0 & 0 & 0 \\
\hline & 3500 & 0 & 0 & 0 & 0 & 0 & 0 & 0 & 0 & 0 & 0 \\
\hline & 4000 & 0 & 0 & 0 & 0 & 0 & 0 & 0 & 0 & 0 & 0 \\
\hline & 4500 & 0 & 0 & 0 & 0 & 0 & 0 & 0 & 0 & 0 & 0 \\
\hline & 5000 & 0 & 0 & 0 & 0 & 0 & 0 & 0 & 0 & 0 & 0 \\
\hline & 5500 & 0 & 0 & 0 & 0 & 0 & 0 & 0 & 0 & 0 & 0 \\
\hline & 6000 & 0 & 0 & 0 & 0 & 0 & 0 & 0 & 0 & 0 & 0 \\
\hline & 6500 & 0 & 0 & 0 & 0 & 0 & 0 & 0 & 0 & 0 & 0 \\
\hline & 7000 & 0 & 0 & 0 & 0 & 0 & 0 & 0 & 0 & 0 & 0 \\
\hline & 7500 & 0 & 0 & 0 & 0 & 0 & 0 & 0 & 0 & 0 & 0 \\
\hline & 8000 & 0 & 0 & 0 & 0 & 0 & 0 & 0 & 0 & 0 & 0 \\
\hline & 8500 & 0 & 0 & 0 & 0 & 0 & 0 & 0 & 0 & 0 & 0 \\
\hline & 9000 & 0 & 0 & 0 & 0 & 0 & 0 & 0 & 0 & 0 & 0 \\
\hline
\end{tabular}

Figure 1: Power command Engine Control Matrix

Figure 1 shows that when all values are set to zero there is no change in the engine, but when the values are updated with a number other than zero the engine is changed at that specified matrix location. The Dynojet 
Autotune allows us to automatically populate these values. We were able to specify the desired Air Flow Ration (AFR) with this Autotune function. Once the AFR has been specified, the Autotune repopulates the matrix shown in Figure 1 for the desired AFR. This matrix is perfected the longer the snowmobile runs.

Next, we installed an ethanol sensor to the machine. The sensor reads the ethanol content, and a program is run to inform the Autotune what content of ethanol is in the fuel. This allows the Autotune to adjust the AFR corresponding to the level ethanol content. Running a lean AFR and an ethanol fuel we were able to reduce the stock $165 \mathrm{HP}$ to the required $130 \mathrm{HP}$, and increase the fuel efficiency of the machine.

\subsection{Ceramic Blanket Insulation}

The team chose to focus on reducing the overall noise levels of the machine. Because we are using a 2-stroke engine noise levels are automatically higher. Ceramic blanket was utilized in key locations on the machine to help reduce noise levels. The blanket was used in the engine compartment were the expansion chamber and catalytic converter are located. The box modified to enclose the muffler was also filled with ceramic blanket to help muffle the noise it created. The team believes that this along with changes to the muffler design will decrease our overall noise level significantly to better score in the noise competition.

\section{Team Organization and Time Management}

\subsection{Gantt Chart}

Team meetings were held weekly among the team members alone to monitor the timeline of the project. Biweekly meetings were held with the mentor of this project. The mentor provided instruction on general engineering issues and engineering project management. An individual design notebook was also used by each member of the team to record their individual progress and measure their contribution to the team.

\subsection{House of Quality}

To meet all our customer requirements for this project, a house of quality was made. This helped the team identify what requirements needed to be met and provided direction for where focus should be placed on modifications being made. This was used as reference for the team to see how changes made to the snowmobile resulted in a negative correlation or positive correlation.

\section{Accurate description of the build items}

Table 1 lists the required data for the build items.

Table 1: Required data

\begin{tabular}{|c|c|}
\hline Chassis & Polaris \\
\hline Manufacturer & 2017 \\
\hline Model & Switchback Assault 144 \\
\hline $\begin{array}{c}\text { year of } \\
\text { production: }\end{array}$ & \\
\hline Engine & Liberty \\
\hline Manufacturer & Gasoline \\
\hline Fuel & Engine \\
\hline Model & 2 \\
\hline Stroke & $799 \mathrm{cc}$ \\
\hline $\begin{array}{c}\text { Combustion } \\
\text { volume }\end{array}$ & $130 \mathrm{HP}$ \\
\hline $\begin{array}{c}\text { peak } \\
\text { horsepower }\end{array}$ & \\
\hline
\end{tabular}




\begin{tabular}{|c|c|} 
& \\
\hline Track & \\
\hline Manufacturer & Camso, 5413073 \\
\hline Style & Series 4, 144 x 2, 2.52 \\
\hline Traction studs & not allowed \\
\hline & \\
\hline Muffler & \\
\hline Manufacturer & Flowmaster 842515 \\
\hline $\begin{array}{c}\text { Student } \\
\text { designed }\end{array}$ & $2^{\prime \prime}$ x 3" x 7" box \\
\hline & \\
\hline $\begin{array}{c}\text { Catalytic } \\
\text { Converter }\end{array}$ & \\
\hline Manufacturer & Universal Catalytic \\
\hline Convertor \\
\hline Style & 425250 Series Direct Fit \\
\hline Skis & \\
\hline Stock & PRO-STEER ski \\
\hline
\end{tabular}

Our team will be competing in the Internal Combustion (IC) class for the 2019 Clean Snowmobile Challenge. Modifications made by the 2018 team were used to better prepare this snowmobile for this year's competition as well as modifications made by this team for future events.

\section{Baseline Tests}

This is the third semester our team has had the 2017 800H.O. Polaris Switchback Assault 144. During the fall semester the team worked on running baseline testing. After modifications were made to the machine the team compared the final results to the baseline testing to make sure that the changes positively affected the performance of the machine.

\subsection{Horsepower Baseline build items description}

A dynamometer was attached to the machine to measure the horsepower before making modifications. We used a Land and Sea Dynomite Dynamometer for this testing. The clutch is removed, and the dynamometer is installed in its place and applies a load with water pressure. We could record HP and torque values during this testing. Figure 2 shows an example output from the dynamometer.

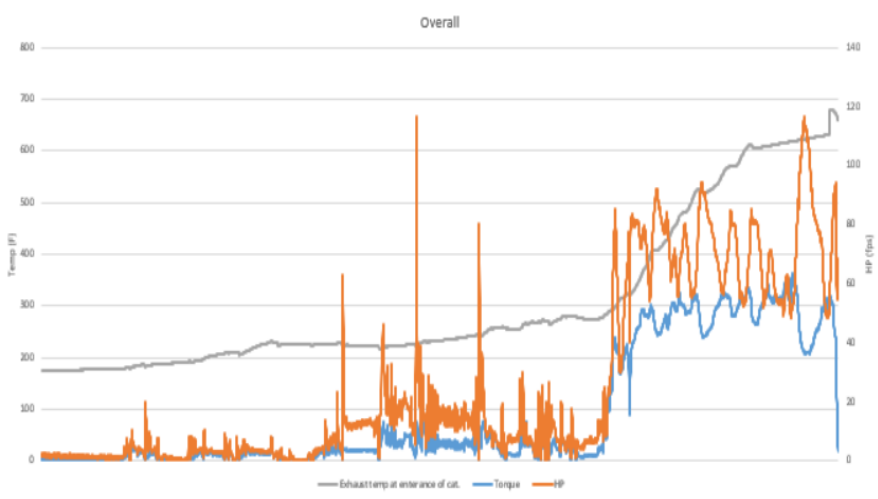

Figure 2: Sample of HP data collected during testing 


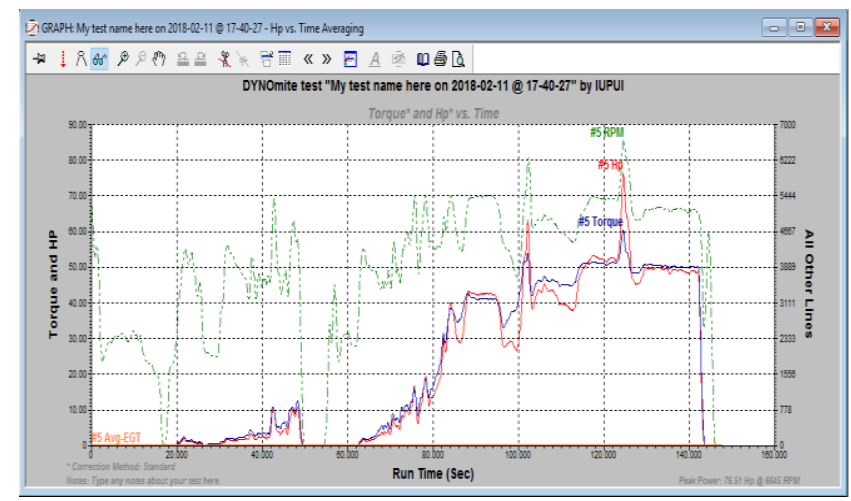

Figure 3: Land \& Sea DYNO-mite Dynamometer sample output

\subsection{Emissions Baseline}

A Huapeng HPC501 emissions tester was used to measure the baseline emissions of the machine. This tester measures nitrous oxide and hydrocarbon in parts per million. It measures carbon dioxide, carbon monoxide, and oxygen as a percent of the gas flow. Using this information, the device is able to calculate the corresponding lambda value. After the test is finished the machine prints out the high, low, and average value.

\subsection{Noise Level}

A Larrison Davis sound meter was used to measure the noise level of our machine. The device allowed us to first zero out background noise, and then run the snowmobile to measure the decibel level. We then used this baseline data to determine what the plan of action would be for redesigning the exhaust system.

\subsection{Exhaust System}

The goal for the modified exhaust system was to reduce the harmful emissions, and noise levels of the machine. The team chose to use a three-way catalytic converter and muffler to replace the existing exhaust system on the machine. The team chose to go with a larger catalytic converter and place the muffler on the sled behind the driver. Figure 4 shows an example of the chosen design.

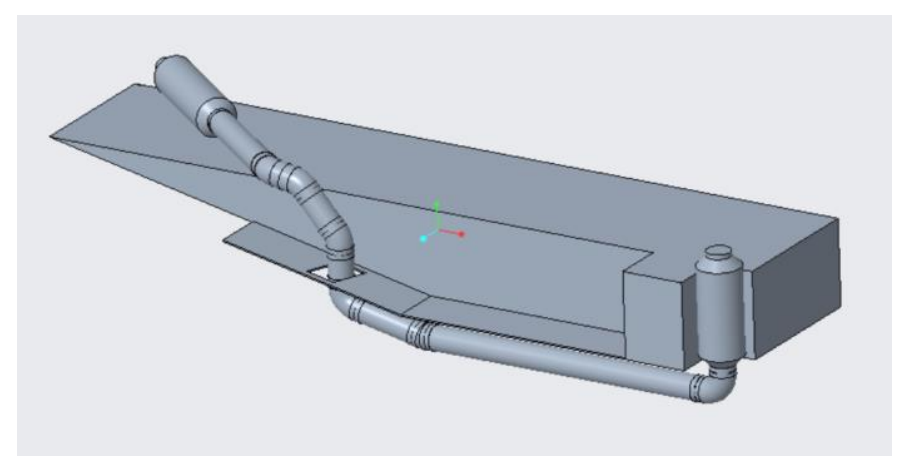

Figure 4: Exhaust system design

Shown in Figure 4, the catalytic converter is placed inside the engine compartment with the expansion chamber. The muffler is extended to the back of the snowmobile to the area behind where the driver sits.

\subsection{Catalytic Converter}

Our 2018 CSC team worked with Faurecia to find a catalytic converter best suited for our needs. Faurecia donated a three-way catalytic converter for the team to use to make the modifications to the exhaust. The threeway design of the catalytic converter will help to reduce the harmful emissions of the harmful gases 
$\left(\mathrm{NO}_{\mathrm{x}}, \mathrm{C}_{x} \mathrm{H}_{y}\right.$, and $\left.\mathrm{CO}\right)$. Inside the catalytic converter there is a catalyst that creates chemical reactions within the harmful gases. Non-harmful molecules like $\mathrm{H}_{2} \mathrm{O}, \mathrm{N}_{2}$, and $\mathrm{CO}_{2}$ are created from the reaction of the harmful gases. The gases pass through a honeycomb catalyst filter which causes the chemical reaction.

\subsection{E-Score Calculation and Results}

Measurements for emissions levels were taken both before and after making modifications to the exhaust system to compare the results. The tests were performed at several different horsepower levels. We were able to find the speeds that emit the most by taking the measurements at different HP levels. For more graphs and analysis on the emissions before and after the exhaust mods see the appendix.

To calculate the E-Score, knowing the Carbon Monoxide (CO), Hydrocarbon (HC), and NOx measurements in $\mathrm{g} / \mathrm{kW}$-hr. Equation 1 shows the E-score equation, which quantifies the emission of outputs for the snowmobile.

$$
\text { E-score }=100\left(1-\frac{H C+N O x-15}{150}\right)+100\left(1-\frac{C O}{400}\right)
$$

(Equation 1)

The $\mathrm{CO}, \mathrm{HC}$, and NOx measurements before and after modifications were implemented to the snowmobile at designated horsepower outputs.

To calculate the emissions rate (g/HP-hr) for each emission at the designated HP, we used the emission rate equations provided by the EPA. They are listed below.

$$
\begin{array}{cc}
E R=\left(1.912 \times 10^{-3}\right) \frac{C_{d} Q T}{H P \cdot h r} & (\text { NOx Equation }) \\
E R=\left(1.164 \times 10^{-3}\right) \frac{C_{d} Q T}{H P \cdot h r} & \text { (CO Equation }) \\
E R=\left(1.833 \times 10^{-3}\right) \frac{C_{d} Q T}{H P \cdot h r} & (\text { HC Equation })
\end{array}
$$

where

$$
\begin{aligned}
& C_{d}=\text { Measured } \mathrm{CO} \text { concentration in ppmv } \\
& Q=\text { Stack gas volumetric flow rate, in standard cubic meters per hour, dry basis } \\
& T=\text { Time of test run, in hours } \\
& H P \cdot h r=\text { Brake work of the engine, in HP-hr }
\end{aligned}
$$

The Stack gas volumetric flow rate was determined by

$$
Q=\left(\frac{\text { Exhaust Temp. }\left({ }^{\circ} \mathrm{F}\right)+460}{540}\right) \times \text { Intake Airflow }
$$

We assume the Exhaust Temp. is $1200^{\circ} \mathrm{F}$ based on reference provided by Donaldson data sheet. We calculated the Intake Airflow to be $34 \mathrm{cfm}$. Assuming volumetric efficiency to 0.8 and the RPM is 3000 . The time T used for the test run is 60 seconds.

\subsection{Muffler Noise Reduction}

The team is using a two stroke $800 \mathrm{cc}$ snowmobile engine which is loud to start. Knowing this, reducing the noise level of the machine was very important to the team. Our 2018 CSC team chose to add a muffler system in the exhaust redesign to help reduce the noise produced by the engine. 
The SAE rules state that our snowmobile must not exceed more than $67 \mathrm{~dB}$ of noise at 50 feet. The team looked at several different mufflers and did extensive research to select the optimal design we should use. The parameters we considered during our research included: (1) Non-restrictive to exhaust flow, and (2) Extensive noise reduction

\subsection{Exhaust system assembly}

Figure 5 shows the full assembly of our redesigned exhaust components. At (1) the exhaust flows into the catalytic converter after passing through the stock expansion chamber. After leaving the catalytic converter the piping is run to the back of the snowmobile to the area behind the driver seat and is run to the muffler. At (2) exhaust gas enters the muffler and then exits into the air.

To avoid a thermal event, we chose to use a high temp exhaust wrap to help insulate the entire exhaust system assembly. The insulation will also help with noise reduction. The plastic panels of the snowmobile will be insulated with the ceramic wrap to also help dampen noise. We believe that our exhaust system will perform well in the 2019 SAE CSC.

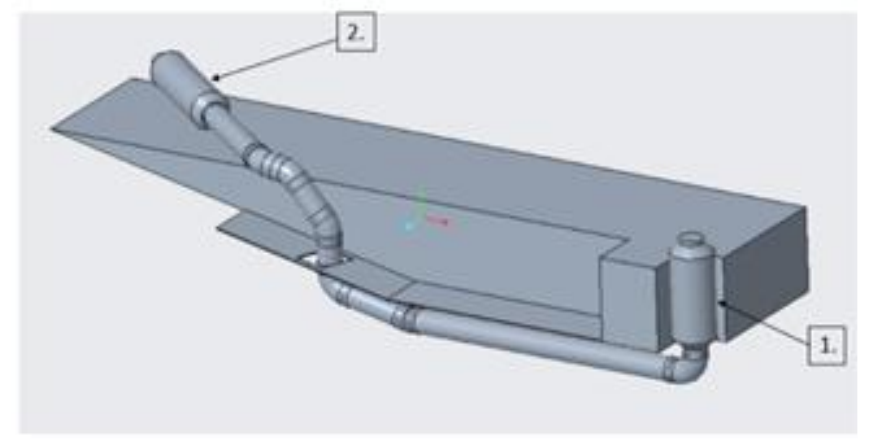

Figure 5: full assembly of our redesigned exhaust components.

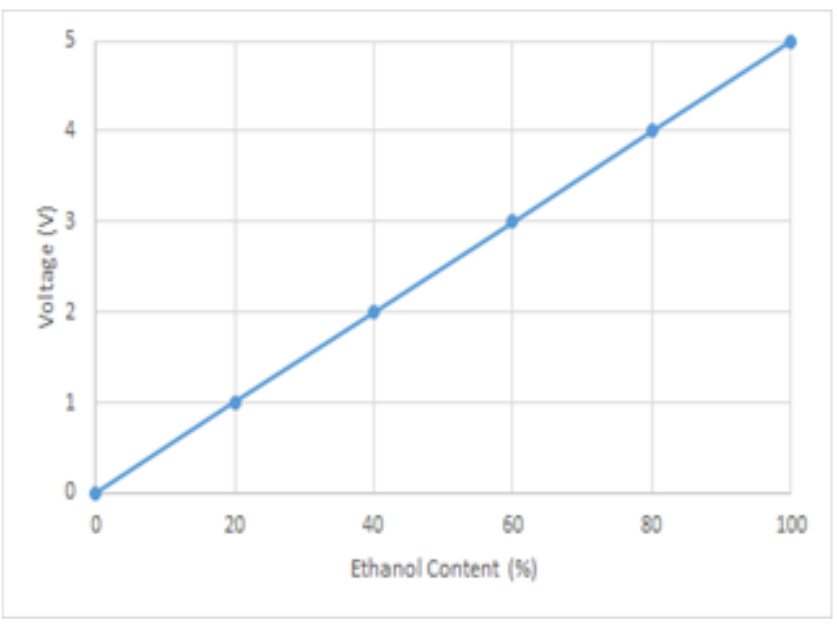

Figure 6: Ethanol Content voltage conversion

\subsection{Engine Control Unit}

To meet the requirement of the 2019 Snowmobile Challenge the team was tasked with modifying the snowmobile to be capable of running off a certain ethanol/gasoline blend. The blend used at the competition could range between E0 to E85. To compensate for the unknown blend of fuel, the team chose a Power 
Commander (PCV) Fuel Injection Module. The PCV is paired with the original ECU to be able to modify the air-fuel-ratio to run leaner.

\subsection{Flex Fuel Sensor}

Our team chose a commercially available flex fuel sensor to use for the snowmobile. This sensor was place in fuel line on the return side, between the fuel tank and pressure regulator. Based on the percent of ethanol in the fuel, the sensor gives off a frequency signal. The Power Commander V could not interpret this frequency signal, so the signal had to be converted into a voltage signal between $0-5 \mathrm{~V}$ instead. The frequency signal was converted by using an ethanol content fuel temperature gauge. The measured voltage was then plugged into the analog input of the Power Commander so the ethanol content could be read. Figure 6 shows the ethanol content voltage conversion.

\subsection{Engine Tuning}

To tune the Power Commander to run off ethanol fuel, the ECU had to be trained to recognize what percent ethanol equaled what voltage. We used 91 Octane fuel to run through the snowmobile to see what voltage value what produced when the sensor read 0\% ethanol. Then we used E85 fuel through the snowmobile to perform the same task. We then plotted the data on a graph in a linear fashion to equate the ethanol percent to the output voltage, as seen in Figure 7.

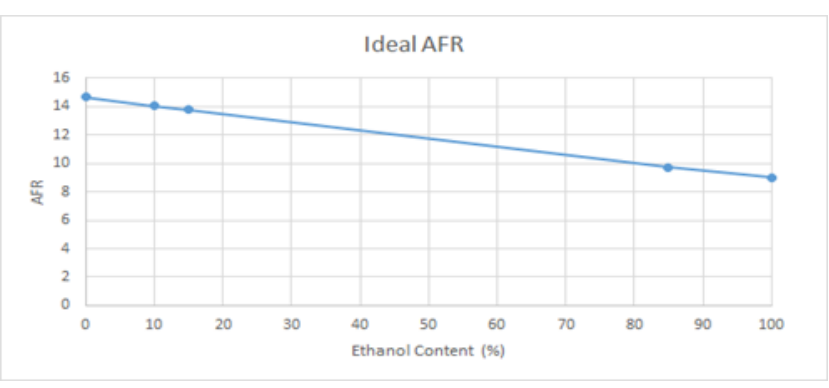

Figure 7: Equating ethanol percentage to output voltage

\subsection{Engine Air-Fuel-Ratio}

To lower emissions and horsepower, we had to modify the air-fuel-ratio. The snowmobile we chose to use for the competition contains an 800cc engine, which according to factory standards, produces 160 horsepower [8] [9]. To avoid disqualification and to meet the SAE standards for the 2018 snowmobile competition, the horsepower of the engine had to be lowered. To fulfill this, we increased the target AFR by utilizing the Power Commanders fuel curve. Theoretically making the engine run leaner. Running the engine leaner means the emissions of the snowmobile were theorized to be lowered and the horsepower of the engine met the competition's standards.

\section{Summary}

Our 2019 SAE Team has re-engineered a 2017 Polaris Switchback Assault to be cleaner, quieter, and more fuel efficient, while maintaining the practicality of the vehicle. The addition of an aftermarket muffler and catalytic converter coupled with a remapping of the ECU are the modifications made by the team to achieve this goal. The total cost for the modifications makes these modifications a cost-effective solution. The modifications made by the team this year will help better prepare the team for future SAE events as well. Our team has been able to utilize advanced methods for testing and measuring the engine with recent acquired dynamometers and emission sensors. The team is on schedule to compete in the competition, due to effective time management and 
communication. Our team hopes to gain valuable insight from the competition itself to help future teams succeed.

\section{Ongoing and future directions}

This is the second year that our team has entered in the SAE Internal Combustion (IC) class Clean Snowmobile Competitions. We have built off last year's progress and laid the foundation for future semesters in regard to our test equipment and methods, and research and development.

\section{Acknowledgment}

We would like to give our thanks to our sponsors. First, to Polaris for donating the 2017 Polaris Assault 800cc, and second to Dynojet for the Power Commander V Fuel Injection Kit. We would also like to thank The Modal Shop MTS Systems Corporation for supplying noise level testing equipment for this competition.

\section{References}

1. N. Skillicorn, "What Is Innovation? 15 Experts Share Their Innovation Definition." 4 November 2016. [Online]. Available: www.ideatovalue.com/inno/nickskillicorn/2016/03/innovation-15-experts-shareinnovation-definition/.

2. S. Foreman, "Best High Flow Catalytic Converter in the Market Today?" 31 July 2017. [Online]. Available: innovatecar.com/best-high-flow-catalytic-converter.

3. Ålander, "Particle Emissions from a Small Two-Stroke Engine: Effects of Fuel, Lubricating Oil, and Exhaust After treatment on Particle Characteristics," Aerosol Science and Technology, pp. 39(2):151$161,2005$.

4. B. Kimbrough, "Understanding Muffler Design and Sound Absorption Strategies," 14 March 2014. [Online]. Available: www.rodauthority.com/tech-stories/exhaust/understanding-muffler-design-andsound-absorption-strategies.

5. Society of Automotive Engineers, "Clean Snowmobile Challenge Rules," 2018.

6. Haltech, "Flex Fuel Sensor Explained," [Online]. Available: http://www.haltech.com/flex-fuel-sensorexplained/.

7. [Air to Fuel Ratio (AFR)," [Online]. Available: www.ultragauge.com/customer_support/knowledgebase.php?article=29.

8. W. Mitianiec, "Comparison of Performance of Two-stroke Engine With Catalytic Converter," Journal of Kones Combustion Engines, pp. 8:129-137, 2001. 